\title{
Analysis of a Skid Type Landing Gear of a Rotary Wing UAV by Experimental and Numerical Methods
}

\author{
O. Yildirim ${ }^{a}$, E. GÜNAY ${ }^{b, *}, \ddot{O} \cdot \mathrm{AnIL}^{c}$, C. AYGÜN ${ }^{d}$ \\ ${ }^{a}$ Fifth Air Force Base Maintenance Center, İstanbul Yolu, 12 Km. Etimesgut, Ankara, Turkey \\ ${ }^{b}$ Gazi University, Engineering Faculty, Mechanical Engineering Department, Ankara, Turkey \\ ${ }^{c}$ Gazi University, Engineering Faculty, Civil Engineering Department, Ankara, Turkey \\ ${ }^{d}$ Gazi University, Engineering Faculty, Mechanical Engineering Department, Ankara, Turkey
}

\begin{abstract}
The objective of this study was to analyze the results obtained from tests done by simulating the crash landing of a rotary wing unmanned air vehicle with a skid type landing gear. The experimental and computational methods were used in the simulation tests. In the first portion of the test; namely with the experimental method, the impact loads induced by the simulated crash landing and the stresses, strains, deformations generated by these loads, were recorded by drop test apparatus. In the second portion of the test with the computational method, free falling of the skid type landing gear was modeled and crash landing test was simulated numerically by using ANSYS code. Experimental methods were applied on four skid landing gear specimens with different shapes. Each of the test samples used in the following test was evolved because each sample was developed and redesigned based on the feedback results obtained from the former test.

The first three test specimens were manufactured from 2024 T3, 7075 T6 and 6061 T6 aluminum alloys respectively and all of them were curved in $\Pi$-form with a solid cross section. The last and fourth specimen was also manufactured from $6061 \mathrm{~T} 6$ aluminum alloy and it was curved in a hollow semi-circle form ( $\cap$-form). It is concluded that the last and fourth developed specimen was the best in absorbing the impact energy and enduring the crash.
\end{abstract}

DOI: $10.12693 /$ APhysPolA.127.1170

PACS: 81.05.Bx, 45.20.da, 45.50.Tn, 02.70.Dh, 04.80.Cc, 06.30.-k, 45.20.D

\section{Introduction}

Development of Unmanned Aerial Vehicle (UAVs) is an increasingly popular research in both academic and industrial fields. There is a wide range of applications performed by UAVs, such as traffic surveillance [1], reconnaissance [2], search and rescue [3], stochastic patrolling and collision avoidance-fire detection [4], fire detection [5], cinematography, and exploration. Compared with fixed-wing UAVs, helicopters are capable of performing missions in high risk and demanding environments with exclusive capabilities including hovering, vertical takeoff and landing in limited launching spaces, and extremely agile maneuvering. With the growth of electronic technology, onboard avionics are shrinking in size and weight which decreases the payload of the helicopter. Thus, the development of a UAV with a small-scale low-cost helicopter becomes possible and has been investigated by a number of research institutes. For example, the robotics institute at Carnegie Mellon University (CMU) [6], the MIT UAV team [7, 8], the University of Berkeley aerial robots team [9], Georgia Tech [10], the Stanford University [11] and the Bandung Institute of Technology (ITB) Department of Aeronautics and Astronautics [12], have developed fully or partially autonomous helicopters over the past decade.

\footnotetext{
* corresponding author; e-mail: egunay@gazi.edu.tr
}

Mikhailova [13] proposed a finite element model to analyze the landing of a helicopter numerically. Mikhailova et al. [14-15] developed three-dimensional design model of a helicopter tubular skid landing gear based on the application of the large beam displacement theory. The analysis of a real helicopter structure was given, that confirms sufficient validity of calculation results, obtained using the model developed by comparing with the numerical and experimental values. Kim et al. have studied the nonlinear crash behavior of the skid landing gear of helicopter. Detailed three-dimensional finite element model with variable thickness and material nonlinearity was constructed for required impact design conditions [16].

In this study, an unmanned aerial vehicle with a skid type landing gear was subjected to simulated loads and the resulting stresses and deformations resulting from these loads were studied in detail. The analyses were carried out in two different stages using both experimental and computational methods. The experimental results which were obtained by using the data of accelerations, stresses, strains, speeds and the mass were compared with the results of finite element analysis achieved by using ANSYS LS-DYNA software. Thus it became possible to verify experimental results by the numerical analysis techniques. Experimental methods were conducted for four different type of specimens. These four specimens were not manufactured simultaneously but in fact, each specimen was manufactured in conjunction with the feedback data which was obtained from the previous experiment. Thus, it was possible to manufacture 
each specimen one after another. The first three specimens were manufactured from 2024 T3, 7075 T6 and 6061 T6 Aluminum alloys, sequentially. With the conduction of fourth and the last experiment, by considering and analyzing the obtained data, it was concluded that the tube specimen, manufactured from circular crosssectioned material and formed in $\cap$-shape was the optimum model in absorbing the nearly entire impact energy. Consequently, the fourth model was modeled in the ANSYS finite element software by the implicit dynamics module (LS-DYNA). The input data obtained during experiments were applied to the ANSYS code and with this procedure the final results were reached [17].

\section{Experimental studies}

Experimental studies performed on four specially produced test skid girder specimens and free drop tests were carried out and controlled by using the electronically conducted test devices. In the experimental studies, the examined parameters were the geometric features of the landing gear tubular prototype and the kind of material used in the formation of the specimen. Experiments were performed in the experimental setup given in Fig. 1. The tests were carried out with the free drop testing equipment and experimental setup. This laboratory equipment enables one to perform dynamic modeling of sudden collision, to implement the experiment and to collect data. Therefore it was the most preferred hardware in the literature. The mechanism has been developed to lower different weights from height of 2.5 meters with a hammer and it was especially developed for crash tests. In other words, these tests were performed for the simulation of the hard landing of unmanned air vehicles to horizontal ground level by raising the test heading to specific altitude and then releasing them from this point. Briefly, this physical experiment was named as the crash landing of air vehicle.

Chrome wheel systems, chrome bearing line and the castermid hummer were preferred to reduce the friction in the experimental setup. The skid girder was attached to the experimental equipment head temporarily with 4 bolts and it was lowered suddenly with the help of a lever. In real life, skid type landing gears were attached to the helicopters with the welded joint connection, and similar four point connections were made in accordance with the original connection type to these experimental prototypes. In the experiments, four different skid girder specimens were tested sequentially. The tested skid girder samples were made of four different Aerospace series aluminum alloy materials. Their mechanical properties are given in Table I.

Specifications of the free drop test-procedures applied to the skid girder prototypes, are given in Table II. Here, $K, \varnothing$ refer to the thickness and diameter of the skid respectively. The total weight of the experimental equipment and their fasteners, which were connected to the tester machine, was $7.5 \mathrm{~kg}$. All of the specimens were released from the height of $500 \mathrm{~mm}$. Tests were performed
Typical mechanical properties of Aluminum alloy used in free drop tests [18].

\begin{tabular}{c|c|c|c|c|c}
\hline $\begin{array}{c}\text { Material } \\
\text { type } \\
\text { Al alloy }\end{array}$ & $\begin{array}{c}\text { Failure } \\
\text { strength } \\
{[\mathrm{MPa}]}\end{array}$ & $\begin{array}{c}\text { Yield } \\
\text { strength } \\
\text { [MPa] }\end{array}$ & $\begin{array}{c}\text { Elasticity } \\
\text { modulus } \\
\text { [GPa] }\end{array}$ & $\begin{array}{c}\text { Fracture } \\
\text { toughness } \\
\text { [MPa] }\end{array}$ & $\begin{array}{c}\text { Poisson's } \\
\text { ratio }\end{array}$ \\
\hline 7075 T6 & 570 & 505 & 72 & 22.5 & 0.33 \\
2024 T3 & 485 & 345 & 73 & 22.3 & 0.33 \\
6061 T6 & 310 & 275 & 69 & 29.1 & 0.33
\end{tabular}

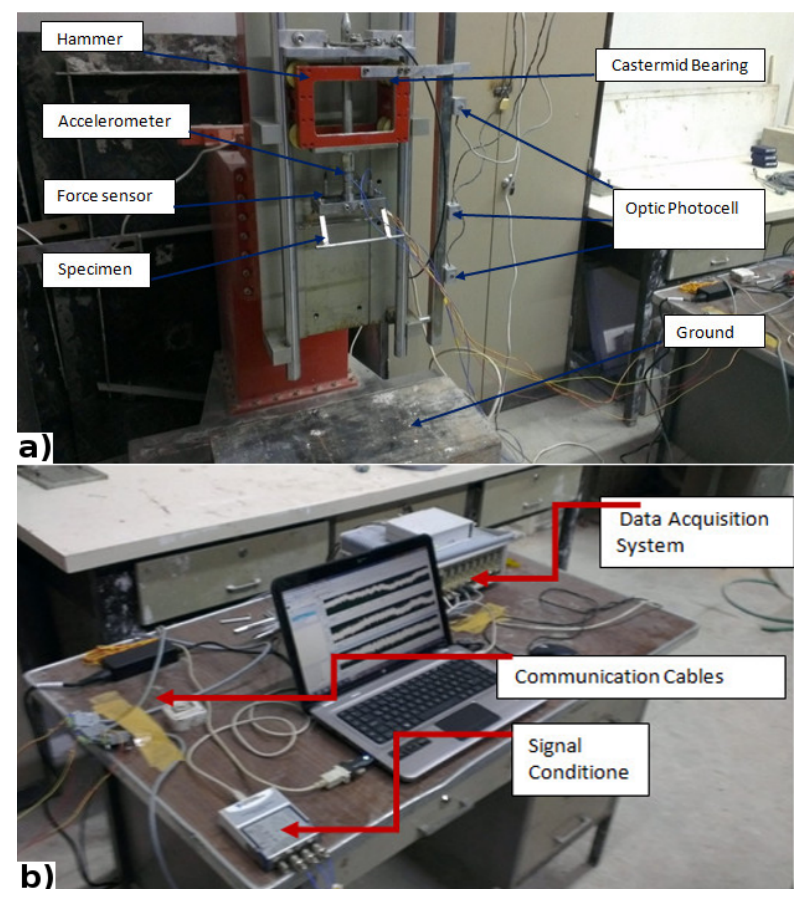

Fig. 1. An overview to the experimental equipment used in the research at the civil engineering mechanics laboratory: (a) impact testing machine, (b) connections to the data acquisition system.

in two stages. In the first phase of the study, only free drop tests were performed experimentally. In the second phase, both experimentally and numerically studies were performed. The first group of experiments was performed using the rectangular tube-shaped landing gears. In the second group of experiments, the circular tubeshaped cross sectional landing gears were manufactured and used. The experiments are described in detail in the following sections.

Specifications of the free drop tests procedures

TABLE II applied on the skid girder prototypes.

\begin{tabular}{c|c|c|c|c}
\hline $\begin{array}{c}\text { Exp. } \\
\text { num- } \\
\text { ber }\end{array}$ & $\begin{array}{c}\text { Height of the } \\
\text { free fall test } \\
{[\mathrm{mm}]}\end{array}$ & $\begin{array}{c}\text { Weight of head } \\
\text { and link element } \\
{[\mathrm{kg}]}\end{array}$ & $\begin{array}{c}\text { Dimension of } \\
\text { skid girder } \\
{[\mathrm{mm}]}\end{array}$ & $\begin{array}{c}\text { Aluminum } \\
\text { type of the } \\
\text { landing } \\
\text { gear }\end{array}$ \\
\hline 1 & 500 & 7.5 & $K=2$ & $7075 \mathrm{~T} 6$ \\
2 & 500 & 7.5 & $K=3.5$ & $2024 \mathrm{~T} 3$ \\
3 & 500 & 7.5 & $K=5.5$ & $2024 \mathrm{~T} 3$ \\
4 & 500 & 7.5 & $\varnothing=3.5$ & $6061 \mathrm{~T} 6$
\end{tabular}




\subsection{Experimental details}

The sample used in the first experiment was $2 \mathrm{~mm}$ thick and made of 7075 T6 aluminum alloy material. The second test sample was $3.5 \mathrm{~mm}$ thick and made of 2024 T3 Al-alloy material. The landing gear of the third test sample was $5.5 \mathrm{~mm}$ thick and made of $2024 \mathrm{~T} 3 \mathrm{Al}$ material. All of these three materials had a $\Pi$ sharpshaped tube structure. They only varied in their tube thicknesses.

Landing gear of the fourth sample of test material, made of Al-alloy $6061 \mathrm{~T} 6$, with $11 \mathrm{~mm}$ diameter and $2.5 \mathrm{~mm}$ wall thickness, had circular cross-section of the $\cap$ soft-shaped tube type. The first test material, coupled to the test rig, is shown in Fig. 1, where it is set to $500 \mathrm{~mm}$ fall in height. The dimensions of the test specimens are given in Fig. 2.
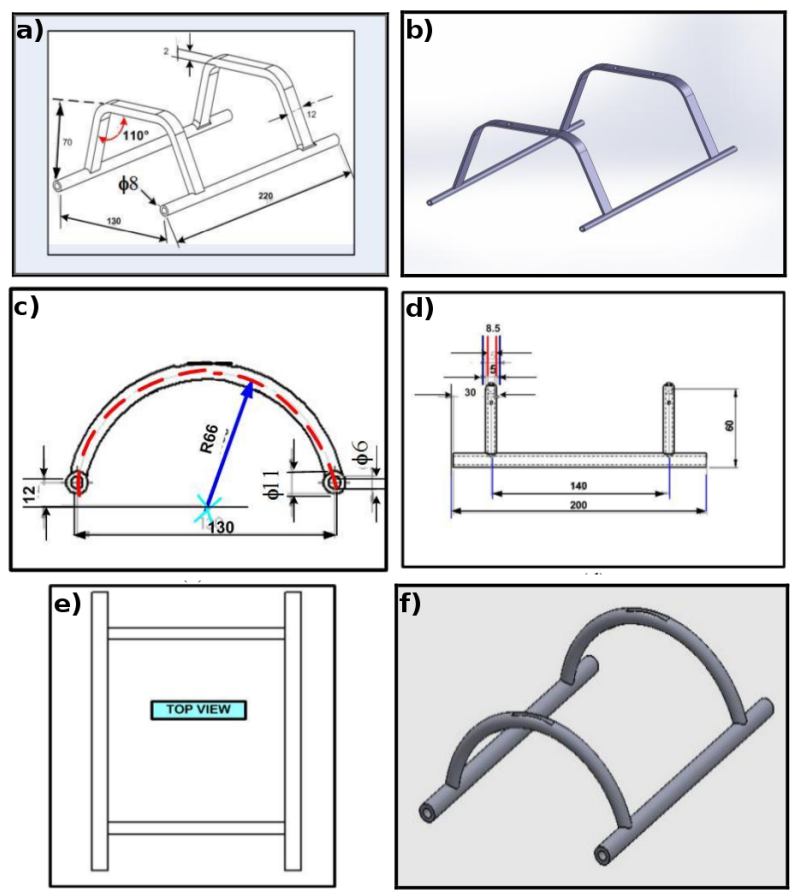

Fig. 2. Geometric dimensions of the test specimens $(\mathrm{mm}):(\mathrm{a}, \mathrm{b}) \Pi$ sharp-shaped skid landing gear test specimen-1, (c) side view $\cap$ soft-shaped of skid, (d) side view of leg, (e) top view of skid, (f) $\cap$ soft-shaped skid landing gear test specimen-4.

\subsection{Experimental results}

The results obtained from the four experiments are listed in Table III. It was concluded that the best stress distributions were measured on the fourth landing gear specimen when compared to other specimens. According to the results obtained from the first three experiments, it was determined that this crash loading caused concentration of maximum stress distributions at the cutting edges of the skid gear, instead of homogeneous stress distribution over the entire structure.

The results were evaluated from two perspectives; the first perspective was related with the cross sections of the skid gear and the second one was related with the shape of its bent segment. In other words, the use of circular cross sections in place of the rectangular ones caused homogeneous distribution of the stresses in the tubular skid gear structures. Application of skid gear arms with circular cross section, instead of sharp corners, caused the uniformly distributed stresses in the structure and thus these geometries have prevented the stress concentration at specific points of the object at crash landing. Photographs of the $\Pi$ sharp-shaped and $\cap$ soft-shaped skid landing gear are shown in Fig. 3a and Fig. 3b respectively. Stress and strain measurements showed a progressively decreasing values, inversely proportional to the cross sectional area of the landing skid gear of specimens 1,2 and 3 respectively. The first tubular specimen had $2 \mathrm{~mm}$ thickness, while the second and third skid landing gear had tube thicknesses of 3.5 and $5.5 \mathrm{~mm}$ respectively. The fourth "bridge cradle" had a thickness of $2.5 \mathrm{~mm}$ (wall thickness), nearly equal to that of the first "bridge cradle". The fourth sample also had a circular shape while the first "bridge cradles" had a rectangular cross section (Fig. 2b, Fig. 2f).

Drop tests and obtained measurements.

TABLE III

\begin{tabular}{c|c|c|c|c|c}
\hline \hline $\begin{array}{c}\text { Experiment } \\
\text { no }\end{array}$ & $\begin{array}{c}\text { Strain } \\
{[\mathrm{m} / \mathrm{m}]}\end{array}$ & $\begin{array}{c}\text { Stress } \\
{[\mathrm{MPa}]}\end{array}$ & $\begin{array}{c}\text { Acceleration } \\
{\left[\mathrm{m} / \mathrm{msec}^{2}\right]}\end{array}$ & $\begin{array}{c}\text { Force } \\
{[\mathrm{kN}]}\end{array}$ & $\begin{array}{c}\text { Velocity } \\
{[\mathrm{m} / \mathrm{msec}]}\end{array}$ \\
\hline 1 & 0.0062 & 445 & 386 & 12.00 & 0.89 \\
2 & 0.0016 & 116 & 302 & 3.50 & 0.85 \\
3 & 0.0022 & 163 & 513 & 7.12 & 0.59 \\
4 & 0.0082 & 568 & 161 & 3.27 & 0.67
\end{tabular}
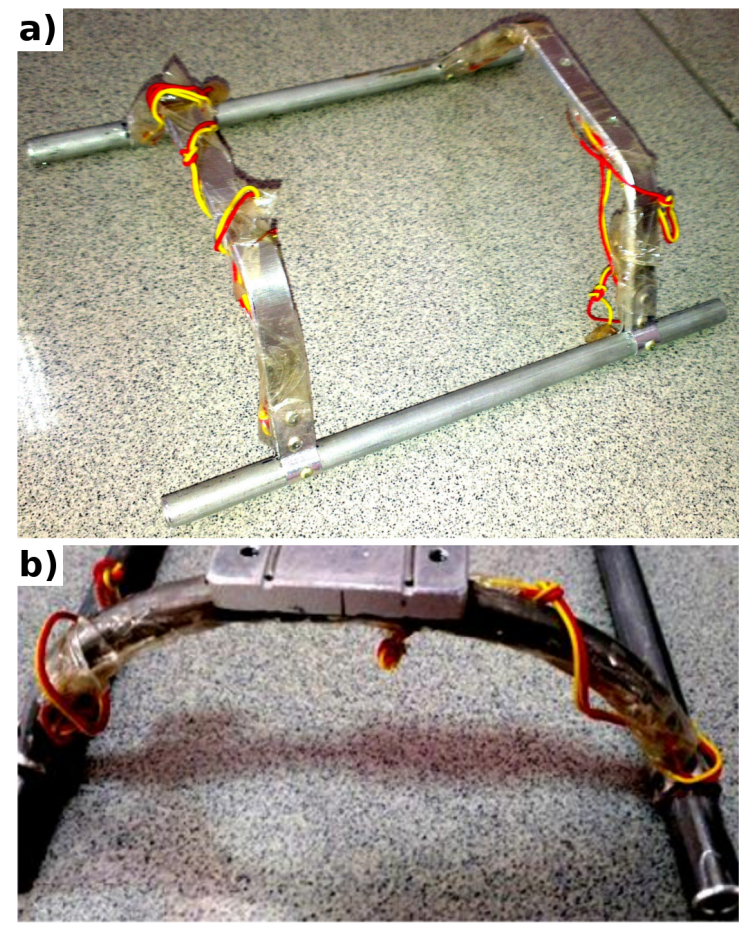

Fig. 3. Views of the test specimens with strain gauges: a) rectangular cross sectional $\Pi$ sharp-shaped, b) circular cross sectional $\cap$ soft-shaped. 
Accelerations of the free falling object and then the time dependent force distributions, just after the impact motion occurred, were measured by strain gauges. Strain gauges were attached to the specimens at four points (Fig. 3).

The acceleration versus time curves of four test specimens are presented in Fig. 4. The load-versus-deflection curves of left and right legs are shown for comparison in Fig. 5. It was shown that the deflections of left legs (Fig. 5a, 5c, 5e, 5g) of the skids were smaller than those of the right legs (Fig. 5b, 5d, 5f, 5h). In comparison of the measured acceleration and force data, it was shown that the fourth, cross tube $\cap$ shaped specimen, gave lower values than the other three samples. The structure of this case, as mentioned above, was most suitable for dissipation of the impact energy.

\section{Numerical simulations of crash landing tests by finite element analyses}

Mathematical modeling of the free fall of the skid type landing gear and its crash to the ground were simulated by two successive numerical solutions. In the first step, the fourth experimental landing skid gear model was validated by using the finite element code ANSYS. In the second step numerical results were modified by using a new design geometry (Table IV) and solution technique. Here, $\varnothing_{F}, \varnothing_{L}$, refer to the diameters of the skid for the first and last simulations. Implicit type free drop FEA was performed with the mesh element Solid-185. The total number of hexagonal mesh elements was 59767 . Fourth landing gear used in the experiment had undergone plastic deformation. Experimental results have shown that the measured stresses were not in the elastic limits and, as a consequence of this, the design of the landing gear was aimed to be done by using the finite element model optimization. The performed FEA for the optimization of the dimension in terms of the radius of the landing skid gear, in terms of "bridge cradle", and "skid" was obtained from five different solutions. In a sense, keeping the design within the elastic limits, was achieved by increasing the size. ANSYS analyses were performed according to the given geometrical dimensions (Table IV).

Used geometric parameters within

TABLE IV ANSYS code.

\begin{tabular}{c|c|c|c|c}
\hline \hline $\begin{array}{c}\text { Model } \\
\text { diameter } \\
\text { (F:First, }\end{array}$ & $\begin{array}{c}\text { Outer } \\
\text { diameter of } \\
\text { the bridge } \\
\text { cradle } \\
\text { [mm }]\end{array}$ & $\begin{array}{c}\text { Inner } \\
\text { diameter of } \\
\text { the bridge } \\
\text { cradle } \\
{[\mathrm{mm}]}\end{array}$ & $\begin{array}{c}\text { Outer } \\
\text { diameter of } \\
\text { the skid } \\
{[\mathrm{mm}]}\end{array}$ & $\begin{array}{c}\text { Inner } \\
\text { diameter of } \\
\text { the skid } \\
{[\mathrm{mm}]}\end{array}$ \\
\hline$\emptyset_{F}$ & 8.5 & 5.0 & 11.0 & 7.5 \\
$\emptyset_{L}$ & 12.0 & 5.0 & 13.0 & 7.5
\end{tabular}

The data obtained from experimental measurements during the time interval between 0 and $1.5 \mathrm{msec}$ (time interval the ground impact) were applied to the last numerical model. As can be seen in Fig. 6, 36 different force values were plotted during 1.5 milliseconds.
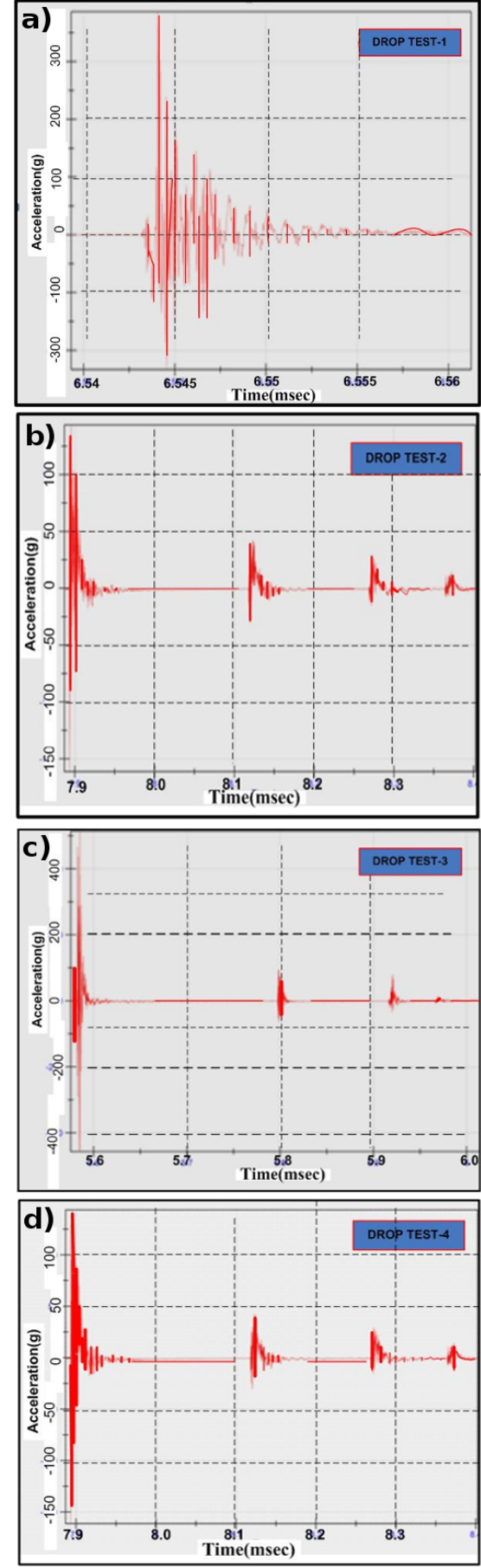

Fig. 4. Gravitational acceleration $(g)$ versus time (msec) curves of test specimens during the impact: (a) specimen-1, (b) specimen-2, (c) specimen-3, (d) specimen-4.

These real values were substituted into the LS-DYN module of ANSYS. The obtained results are listed in Table V. The results agreed reasonably well with those found by using the modified model. Results of application of the FEA model of the stresses generated with crash loading are presented in Fig. 7 as well. Numerical 


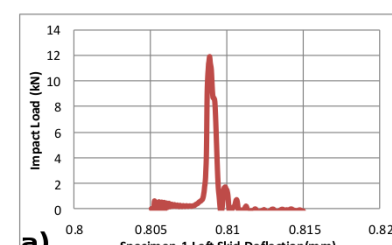

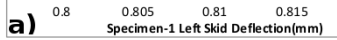

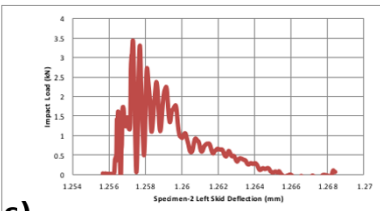

c)

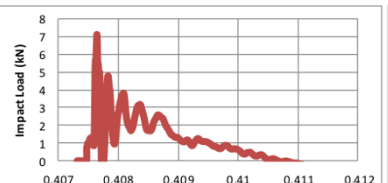

e) $\begin{array}{lllll}0.407 & 0.408 & 0.409 & 0.41 & 0.411 \\ \text { Specimen-3 Left Skid Deflection }(\mathrm{mm})\end{array}$

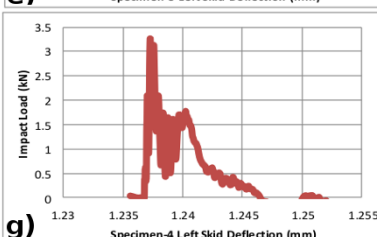

g)

Fig. 5. Impact load $(\mathrm{kN})$ versus displacement (mm) curves of skid gears: left leg of the skids are considered for the specimen- 1 , specimen- 2 , specimen- 3 , specimen- 4 (a, c, e, g) and right leg of the skids are considered for the specimen- 1 , specimen-2, specimen- 3 , specimen-4 (b, $\mathrm{d}, \mathrm{f}, \mathrm{h})$.

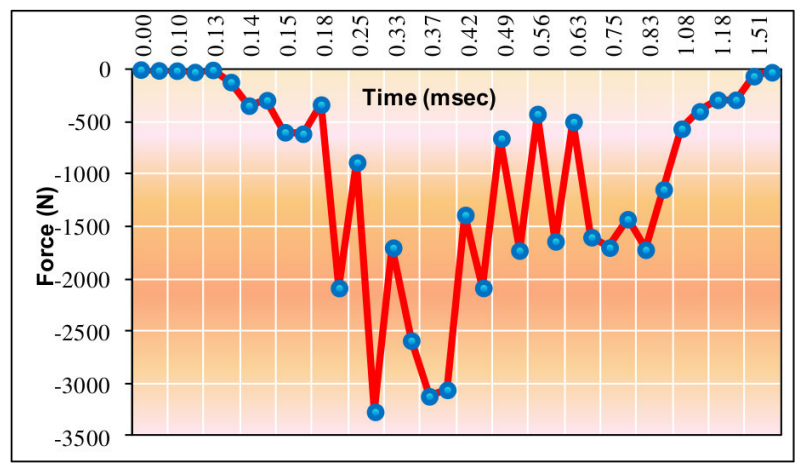

Fig. 6. Determination of the maximum impact load of the specimen- 4 .

Comparison of experimental and numerical results obtained from the fourth specimen.

TABLE V

\begin{tabular}{c|c|c|c}
\hline \hline Model types & $\begin{array}{c}\text { Total displa- } \\
\text { cement } \\
\delta[\mathrm{mm}]\end{array}$ & $\begin{array}{c}\text { Lateral } \\
\text { Strain } \\
{[\mathrm{mm} / \mathrm{mm}]}\end{array}$ & $\begin{array}{c}\text { Stress } \\
\sigma \\
{[\mathrm{MPa}]}\end{array}$ \\
\hline $\begin{array}{c}\text { Free Drop Test } \\
\text { (experimental) }\end{array}$ & 3.92 & $8.2 \times 10^{-3}$ & 568 \\
\hline $\begin{array}{c}\text { FEA-Original Model } \\
\text { (numerical) }\end{array}$ & 3.10 & $7.5 \times 10^{-3}$ & 520 \\
\hline $\begin{array}{c}\text { FEA-Modified Model } \\
\text { (numerical) }\end{array}$ & $8.20 \times 10^{-4}$ & $2.7 \times 10^{-3}$ & 193 \\
\hline
\end{tabular}
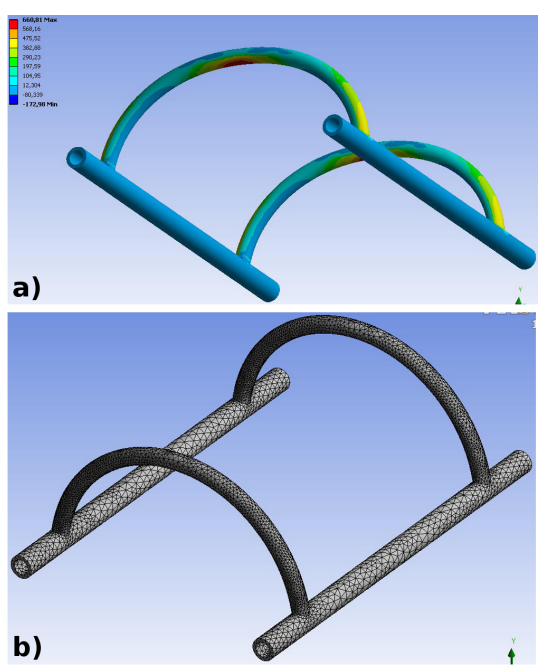

Fig. 7. ANSYS stress solutions for the crash landing of the skid gear (maximum stress : $660 \mathrm{MPa}$ ): (a) average stress distribution on the circular cross sectional $\cap$ soft-shaped landing skid gear, (b) mesh system and hexagonal mesh elements used in ANSYS LS-DYN solution.

and experimental results were verified in terms of stress distributions at the locations where strain gauges were attached to the skid surfaces.

Finite element analysis and experimental results of the fourth experiment are in agreement with an error of $7.1 \%$. Finally, finite element model was developed throughout the optimization of dimensions of the fourth specimen and then the obtained force versus time values were applied to the program in order to simulate the crash landing of skid gears (Fig. 8, Table V). Maximum values obtained for the modified specimen occurred at the middle segment of the bridge cradle as;

(i) the maximum deflection:

$$
\delta_{\max }=0.1067 \times 10^{-3} \mathrm{~mm}(\text { Fig. 8a) },
$$

(ii) the maximum elastic strain:

$$
\varepsilon_{\max }=2.077 \times 10^{-5} \text { (Fig. 8b), }
$$

(iii) the equivalent von-Mises stress:

$$
\sigma_{\max }=98.481 \mathrm{MPa} \text { (Fig. 8c), }
$$

(iv) maximum principle stress:

$$
\sigma_{\max }=114.52 \mathrm{MPa} \text { (Fig. 8d). }
$$

\section{Conclusions}

The results of the verification process, obtained from experimental methods, were taken into account during the numerical simulations, in order to obtain the best design for skid gear. Based on this study the following conclusions were reached:

- The experimental procedures were repeated under the similar conditions by increasing thickness of tubular section of the skid geometry. Thus, the dimensions of finite element model changed accordingly. Though the analysis was validated, it was 

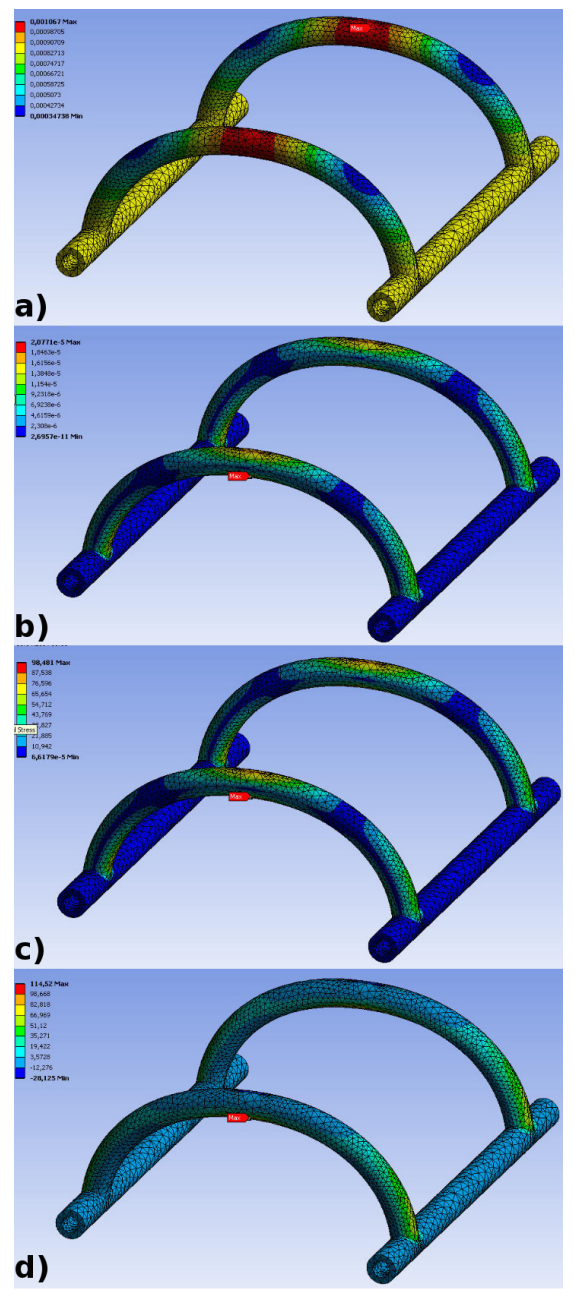

Fig. 8. Numerical results of crach landing test by ANSYS LS-DYN: (a) total deformation $\delta_{\max }$, (b) equivalent elastic strain $\varepsilon_{\max },(\mathrm{c})$ von Mises equivalent stress $\sigma_{\max }$, (d) Principle stress $\sigma_{\max }$.

observed that the prototype specimens of the landing gear manufactured for the fourth experiment still undergo considerable amount of plastic deformation during landing. The analysis was carried out repeatedly with ANSYS in order to obtain an optimized model, and it was showed that the new prototype numerical model of landing gear was 1.5 times safer.

- As the finite element analysis and the experimental stress and strain values were compared, a $9.67 \%$ error was detected.

- As it is concluded from the references cited in the work, the desired feature of a skid type landing gear is that it must be able to absorb the nearly whole impact energy, formed during landing, by remaining in the elastic zone, and when the impact ends, it is expected to regain it's original shape. In our study, this condition was fulfilled with approximately $10 \%$ error, the work was assumed to be complete and it was determined that the landing gear model satisfied physically the desired safety criteria.

\section{Acknowledgments}

The usage of ANSYS code of our study was supported by Gazi University Scientific Research Projects Department with Grant Ref No: 06/2011-57 Drop tests were performed in the Mechanics Laboratory of Civil Engineering Department at Gazi University.

\section{References}

[1] B. Coifman, M. McCord, R.G. Mishalani, M. Iswalt, Y. Ji, IEE Proc. Intell. Transp. Syst. 153, 11 (2006).

[2] A.R. Girard, A.S. Howell, J.K. Hedrick, Proc. $43^{\text {rd }}$ IEEE Decision and Control (CDC), Atlantis, Paradise Island, Bahamas 2004, p. 620.

[3] A. Ryan, J.K. Hedrick, Proc. $44^{\text {th }}$ IEEE Conf. on Decision and Control (CDC-ECC), Seville, Spain 2005, p. 1471.

[4] J. Jackson, R. Bencatel, Z. Hasan, A. Girard, Conf. on AIAA Guidance Navigation and Control, Chicago, Illinois 2009, p.1.

[5] D.W. Casbeer, D.B. Kingston, R.W. Beard, T.W. McLain, Int. J. Syst. Sci. 37, 351 (2006).

[6] O. Amidi, T. Kanade, R. Miller, Proc. American Helicopter Society Conf. on Vision-Based Autonomous Helicopter Research at Carnegie Mellon Robotics Institute, 1991-1997, Gifu, Japon 1998, p. 1.

[7] K. Sprague, V. Gravilets, D. Dugail, B. Mettler, E. Feron, Proc. AIAA Conf. on Digital Avionics Systems Conference, Daytona Beach, FL 2001, p. 1.

[8] V. Gravilets, A. Shterenberg, I. Martinos, K. Sprague, M. Dahleh, E. Feron, IEEE Aerosp. Electron. Syst. Mag., p.38 (2001).

[9] http://robotics.eecs.berkeley.edu/bear/, BEAR:Berkeley Aerobot Team (accessed 8.Dec.2014).

[10] E.N. Johnson, S. Mishra, Proc. AIA A Conf. on Modeling and Simulation Technology, No. AIAA-20024975, Monterey, CA 2002.

[11] http://heli.stanford.edu, accessed 8. Dec. 2014.

[12] A. Budiyono, Aerospace Indonesia Meeting, Bandung, Indonesia 2005, p.1.

[13] S.A. Mikhailov, Conf. on European and International LS-DYNA User, http://www.dynalook.com/ international-conf-2002/Session_14-2.pdf, Detroid 2002

[14] S.A. Mikhailov, L.V. Korotkov, D.V. Nedel'ko, Russian Aeronautics (Iz.VUZ) 53, 369 (2010).

[15] S.A. Mikhailov, L.V. Korotkov, D.V. Nedel'ko, Russian Aeronautics (Iz.VUZ) $\mathbf{5 3 ,} 9$ (2010).

[16] D.H. Kim, Y.S. Kim, Int. J. Mod. Phys. B 22, 1403 (2008).

[17] O. Yildirim, M.Sc. Thesis, Gazi University Graduate School of Natural and Applied Sciences, Ankara 2014.

[18] ASM International Handbook Committee, Metals Handbook, Desk Edition, Eds. J.R. Davis, ASM International 1998. 